\title{
Modern Variants of Technological Schemes \\ for Sewage Purification with the Use \\ of Impulse Cavitation Technology
}

Olga G. Dubrovskaya ${ }^{a}$, Vladimir A. Kulagin ${ }^{a *}$ and Ekaterina S. Sapoghnikova ${ }^{a, b}$ ${ }^{a}$ Siberian Federal University 79 Svobodny, Krasnoyarsk, 660041, Russia ${ }^{b} J S C$ «NPP «Radio» 19 The Decembrists, Krasnoyarsk, 660021, Russia

Received 16.01.2015, received in revised form 02.02.2015, accepted 04.03.2015

The results of research of the systems of oil - containing wastewater conditioning are described. The analysis of existing technological schemes of treatment with definition of their main maintenance deficiencies is carried out and modernized variants of pollution control arrangement are suggested including the cavitation treatment unit, simultaneously performing the functions of physical-chemical treatment and biological impurities disinfection.

Keywords: wastewater, oil products, flotation, biopollutant, cavitation technology, sewage treatment equipment.

\section{Современные компоновки}

технологических схем очистки сточных вод

с использованием кавитационной технологии

\author{
О.Г. Дубровская ${ }^{\mathrm{a}}$, \\ В.А. Кулагин ${ }^{\text {a }}$ Е.С. Сапожникова ${ }^{\mathrm{a}, \boldsymbol{\sigma}}$ \\ ${ }^{a}$ Сибирский федеральный университет \\ Россия, 660041, Красноярск, Свободныий, 79 \\ ${ }^{6}$ Научно-производственное предприятие «Радиосвязь» \\ Россия, 660021, Красноярск, Декабристов, 19
}

Изложены результаты исследований систем кондиционирования нефтесодержащих сточных вод. Проведен анализ существующих технологических схем очистки с определением их основных эксплуатационных недостатков и предложены модернизированные варианты компоновки

(c) Siberian Federal University. All rights reserved

* Corresponding author E-mail address: v.a.kulagin@mail.ru 
очистного оборудования, включающие узел кавитационной обработки, одновременно выполняющий функиии физико-химической очистки и обеззараживания биологических примесей.

Ключевые слова: сточная вода, нефтепродукты, флотация, биополютанты, кавитационная технология, очистное оборудование.

Предлагаемые современные технические решения должны отвечать ряду требований, а именно быть энергоресурсосберегающими, экологически безопасными, экономически целесообразными и вместе с тем высокоэффективными.

Внедряемая технология очистки сточных вод, содержащих нефтепродукты и биополютанты, в основе которой лежит кавитационное воздействие, отвечает вышеуказанным требованиям. К тому же очищенная по данной технологии вода по физико-химическому составу соответствует требованиям по техническим условиям предприятий теплоэнергетического комплекса к оборотной воде.

Кавитационный реактор может быть включён в любой из этапов типовых технологических схем очистки. На рис. 1-3 представлены апробированные принципиальные схемы очистки нефтесодержащих сточных вод с использованием кавитационной установки. Схема очистки нефтесодержащих сточных вод фильтрацией с доочисткой в кавитационном роторном реакторе представлена на рис. 1 .

Технологическая схема включает: коагуляционное осаждение и фильтрование примесей в первой ступени; кавитационную обработку осветленного стока во второй ступени; осаждение продуктов разложения и адсорбированных интермедиатов в третьей ступени очистки. Основной ступенью очистки в данной схеме является внедрение технологии очистки на базе эффектов кавитации для разложения трудноокисляемых веществ.

Согласно литературным данным [1-5], в условиях гидродинамической кавитации можно выделить три зоны, где происходят химические реакции окисления:

- механотермодеструкция летучих соединений и образование $\mathrm{OH}^{-}$-радикалов на границе раздела жидкость - газ;

- механотермодеструкция летучих соединений и образование $\mathrm{OH}^{-}$-радикалов в газовой среде образовавшегося пузырька;

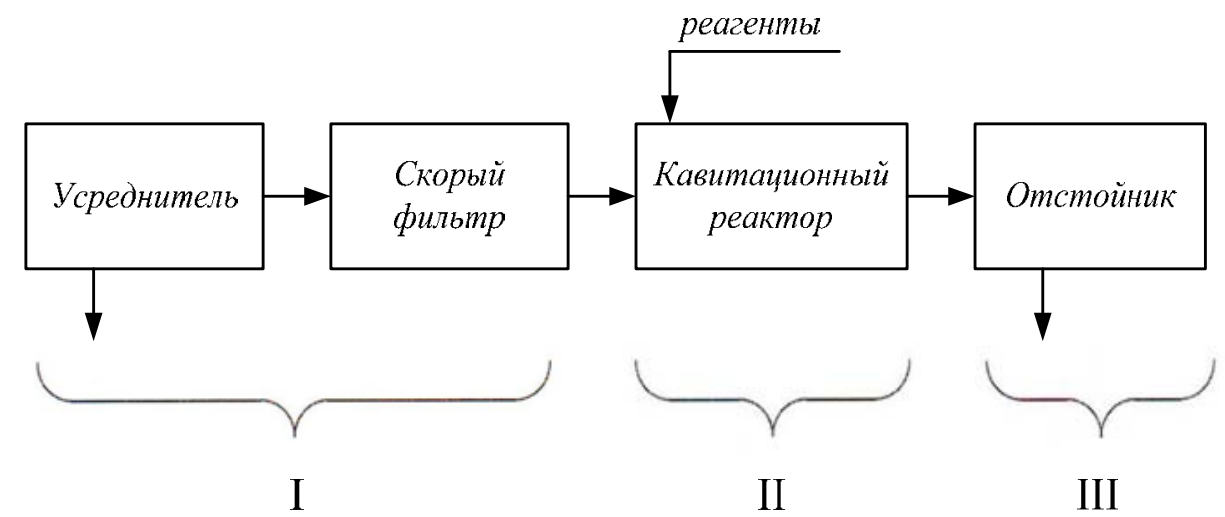

Рис. 1. Схема очистки нефтесодержащих сточных вод с доочисткой в кавитационном роторном реакторе 
- зона в объеме жидкости, куда диффундирует небольшое количество $\mathrm{OH}^{-}$-радикалов, температура при этом на несколько порядков ниже температуры внутри пузырька.

Инициация радикально-цепных реакций окисления субстратов (химических загрязнителей органического происхождения) возможна при добавлении небольшого количества окислителя в зону кавитации, однако активация и кавитационное разложение молекул воды сопровождаются образованием сильных окислителей: перекись водорода, озон и др. Следовательно, искусственное введение окислителей может быть целесообразным лишь с точки зрения сокращения времени кавитационной обработки стока.

Для предотвращения абразивного износа кавитационного реактора и снижения энергозатрат при максимально полном удалении загрязнителей рекомендуется провести начальное осветление стока для удаления взвесей и неэмульгированных органических полютантов, таких как нефтепродукты, жиросодержащие вещества.

Технологическая схема очистки нефтесодержащих сточных вод с примесями поверхностноактивных веществ (ПАВ) и НПАВ представлена на рис. 2. Данная схема работает следующим образом: сточная вода сначала попадает в отстойник со встроенной песколовкой 1 , где отделяются крупные взвеси и неэмульгированные нефтепродукты, затем проходит через скорый фильтр 2, где очищается уже от мелкодисперсных взвесей. Затем предварительно очищенная вода попадает в резервуар с кавитационной установкой лопастного типа 5 , где очищается от эмульгированных нефтепродуктов, одновременно с данным процессом осуществляется пенообразование за счет примесей ПАВ и НПАВ. Образующаяся пена удаляется пеносъёмником и поступает в ёмкость для моющего концентрата 3 с целью повторного использования, очищенная вода поступает в резервуар-накопитель 6 и применяется в качестве технической воды.

Глубокая очистка сточных вод необходима перед использованием их в системах повторного и оборотного водоснабжения промышленных предприятий. Преимущественное применение они находят в системах охлаждающего оборотного водоснабжения, а также в ряде технологических операций, где требования к воде примерно соответствуют показателям качества вод

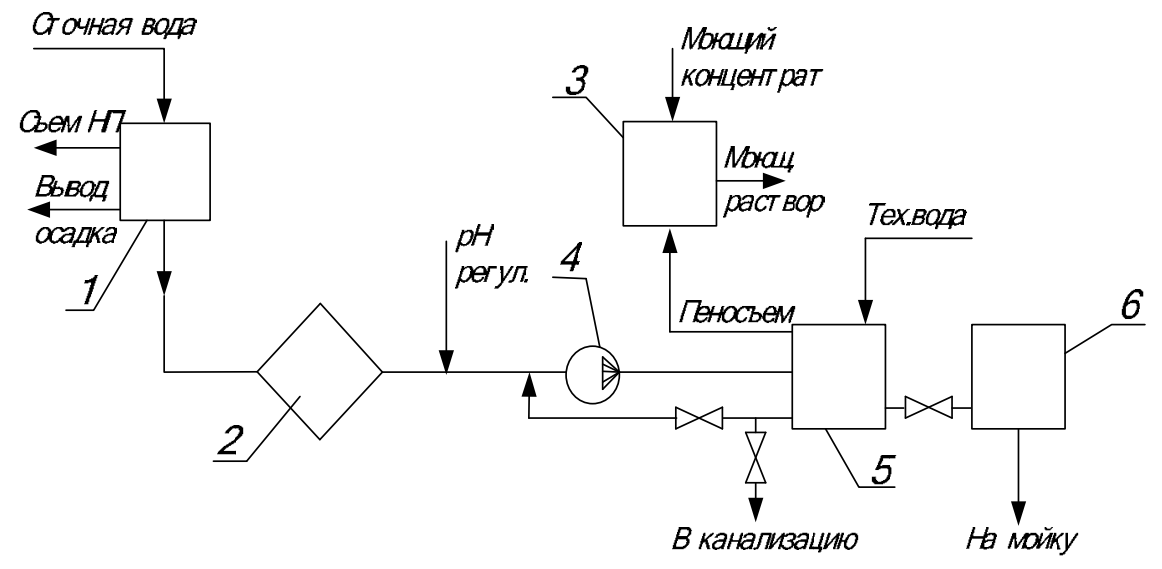

Рис. 2. Схема очистки нефтесодержащих сточных вод с примесями ПАВ и НПАВ с доочисткой в кавитационном реакторе лопастного типа: 1 - отстойник со встроенной песколовкой; 2 - скорый фильтр; 3 - емкость моющего концентрата; 4 - насос; 5 - емкость с кавитационной установкой; 6 - резервуарнакопитель технической воды

$$
-219-
$$


открытых источников. В некоторых случаях эти требования могут быть менее жесткими, чем к качеству воды перед сбросом в водоёмы.

Рассматривая технологические схемы процессов кондиционирования вод с использованием эффектов кавитации, можно отметить, что в промышленном масштабе реализовано только несколько схем. Одна из них разработана в США и получила название $C A V$ - $O X$-процесс $[1,3]$. Данная технология используется для очистки грунтовых вод с низкими концентрациями органических примесей. В этой технологии задействованы: гидродинамическая кавитация, ультрафиолетовое излучение и пероксид водорода как реагент для окисления органических веществ. На рис. 3 показана принципиальная схема для реализации $C A V$ - $O X$-процесса.

Протекающий по данной схеме $C A V-O X$-процесс может использоваться в двух модификациях: применение только кавитационного модуля и применение комбинации кавитационного модуля и УФ-реактора. В данной схеме используется высоконапорный кавитационный реактор проточного типа.

В большинстве технологических схем узлом удаления нефтепродуктов, жиросодержащих веществ, мелких взвесей и частично биополютантов выступают флотационные установки, основным недостатком которых является нестабильность процесса очистки. Эффективность процесса может колебаться в довольно широких пределах: от 20 до 85 \%. Извлечение диспергированных, коллоидных или растворенных примесей воды происходит в результате их прилипания к пузырькам газа, образующимся в жидкости. Агрегаты пузырьков воздуха с примесями всплывают на поверхность, образуя пенный высококонцентрированный слой. Существенное влияние на эффективность флотации оказывает соотношение размеров частицы загрязнителя и газового пузырька, которое определяет эффективность их столкновения и последующего притяжения. Для каждого размера пузырька существует критический размер частицы. Столкновение частиц меньшего размера с пузырьком не происходит. При этом очень мелкие частицы движутся точно по линиям тока жидкости, обтекающей всплывающий пузырек. Поэтому столкновение частицы с пузырьком может произойти, только когда частица проходит вблизи

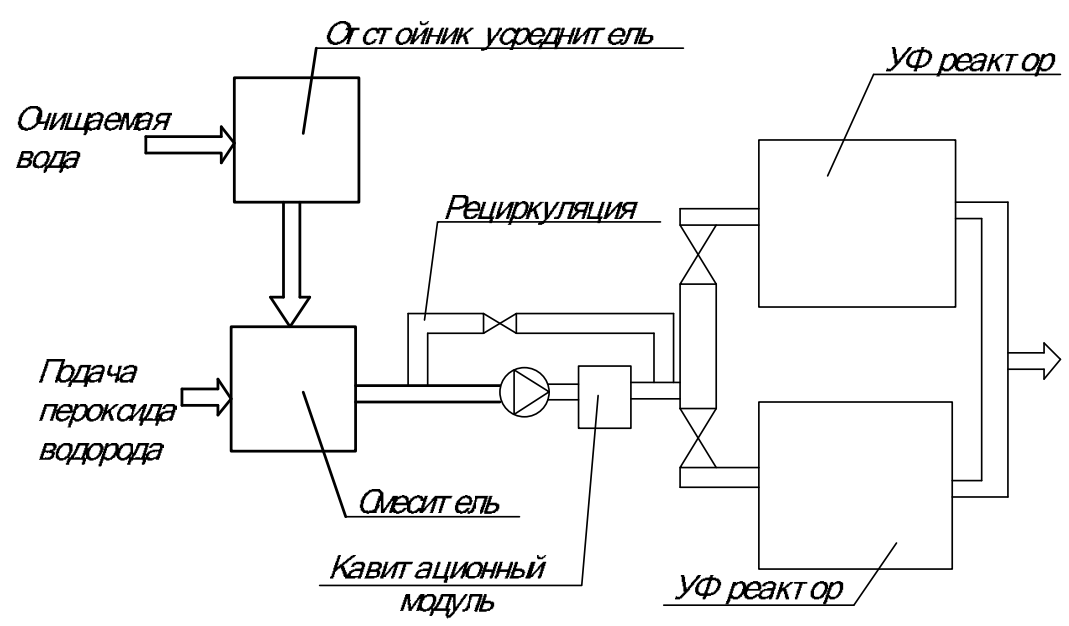

Рис. 3. Схема очистки нефтесодержащих сточных вод с примесями ПАВ и НПАВ с доочисткой в кавитационном модуле с ультрафиолетовым (УФ) реактором 
пузырька на расстоянии одного радиуса частицы. Гидродинамические силы действуют на частицу загрязнителя, как правило, на больших расстояниях от пузырька, и, напротив, на расстояниях, малых по сравнению с размером частицы, превалируют поверхностные силы. Различие в масштабах действия различных сил позволяет отделить этап столкновения от этапа закрепления и условно отнести к этапу столкновения сближение частицы и пузырька до расстояний, на которых действие поверхностных сил становится определяющим [3, 4].

Этап закрепления заканчивается фиксацией частицы на пузырьке, этап удержания частицы на пузырьке - сохранением комплекса «пузырек-частица» до выхода в пенный слой. При ударе минерализованных пузырьков о пенный слой, их коалесценции в пене, съеме пены часть частиц выпадает из пены и возвращается в пульпу, что в целом снижает конечную эффективность флотации. Таким образом, можно сформулировать ряд недостатков флотационной технологии:

- трудности расчета оптимальных технологических параметров - оптимальный технологический режим чаще всего устанавливают опытным путём;

- оптимальный удельный расход воздуха в несколько раз превышает то количество воздуха, которое необходимо для создания условий всплывания агрегатов пузырьков с твёрдыми частицами;

- большой избыток воздуха может привести к тому, что пузырьки будут накапливаться под слоем выделенного шлама и толщина верхнего шламо-воздушного слоя, увеличиваясь, может достичь области гидравлических возмущений, создаваемой впускными устройствами. Это ухудшает эффект флотации, поскольку пузырьки и частицы выносятся с осветленной водой;

- низкий коэффициент очистки;

- образование при окислении высокомолекулярных соединений промежуточных токсичных веществ (повышение индекса токсичности);

- высокая чувствительность к нарушениям технологических параметров флотации;

- энергозатратность - для очистки $1 \mathrm{M}^{3}$ сточной нефтесодержащей воды требуется 0,05-0,08 кВт электроэнергии.

Внедрение в технологическую схему очистки кавитационного реактора позволяет добиться более высокой степени очистки воды, до $99 \%$, с затратами электроэнергии на $1 \mathrm{~m}^{3}$ стока 0,016 кВт и обеспечивает оборотное водопользование, что в итоге для предприятия обернется экономически выгодным режимом водопотребления и снижением эксплуатационных затрат.

Конструкции предлагаемого кавитационного реактора рассчитаны на производительность 5 м³ ч. Рециркуляционный расход воды составляет $20 \%$ от расхода, подаваемого на установку. Для оптимальной работы генератора гидродинамических колебаний ёмкость должна быть круглой либо для простоты встраивания данной технологии в уже существующие установки шестигранной. Целесообразным представляется частичная модернизация существующей технологической схемы кондиционирования сточных вод. Предлагаемое конструктивное изменение вносится после стадии флотационной очистки. Такое решение позволит интенсифицировать процесс очистки сточных вод от высоких содержаний нефтепродуктов и взвешенных веществ, получить необходимую степень очистки сточных вод для оборотного водоснабжения или полностью исключить платежи предприятия за превышение пределов установленных ли- 
митов на сброс сточных вод, что значительно улучшит показатели его природоохранной деятельности, если используется открытая система водоснабжения.

Производственные испытания показали высокую эффективность (табл. 1) кавитационной технологии при очистке сточной воды, загрязненной нефтепродуктами, взвешенными веществами и биологическими загрязнителями. Выявлены основные преимущества использования кавитации по сравнению с напорными флотаторами:

- насыщение жидкости пузырьками практически не зависит от наличия в ней взвешенных веществ;

- возможность очистки стоков с различным качественно-количественным содержанием загрязняющих веществ;

- использование этого мероприятия при модернизации существующего оборудования. Разработанное устройство встраивается во флотационные камеры существующих сооружений без изменения их конструкции;

- возможность автоматизировать процесс очистки;

- снижение эксплуатационных затрат.

Проведено биотестирование с целью рекомендации данной схемы для производственного внедрения. Для определения экологической безопасности предлагаемой технологии кондиционирования была использована сточная вода предприятия теплоэнергетического комплекса. Обоснование возможности использования очищенной воды в оборотном водоснабжении предприятий данной отрасли подтверждено анализом биотестирования на наличие Dafnia и Chlorella. Критерием острой летальной токсичности является гибель $50 \%$ и более дафний в опыте за 96 часов биотестирования. Методика биотестирования на Chlorella основана на установлении различия между интенсивностью роста клеток водорослей в анализируемой пробе (опыт) и культуральной среде (контроль). Критерием токсического действия является снижение на 50 \%

Таблица 1. Результаты обработки сточных вод по существующей схеме и рекомендуемой схеме очистки сточных вод

\begin{tabular}{|c|c|c|c|c|c|c|c|c|c|}
\hline \multirow[t]{2}{*}{ Сооружения } & \multicolumn{3}{|c|}{$\begin{array}{c}\text { Взвешенные } \\
\text { вещества }\end{array}$} & \multicolumn{3}{|c|}{$\begin{array}{c}\text { Нефтепродукты, } \\
\text { мг/л }\end{array}$} & \multicolumn{3}{|c|}{ Биополютанты клеток, мл } \\
\hline & до & после & Э, \% & до & после & Э, \% & до & после & Э, \% \\
\hline \multicolumn{10}{|c|}{ Существующая схема } \\
\hline Аккумулирующая емкость & 777 & 749,8 & 3,5 & 100 & 100 & 0 & 1155133 & 1155133 & 0 \\
\hline Флотационная установка & 749,8 & 164,9 & 78 & 100 & 42 & 58 & 1155133 & 555000 & 48,5 \\
\hline $\begin{array}{l}\text { Общая эффективность } \\
\text { очистки }\end{array}$ & \multicolumn{9}{|c|}{61,50} \\
\hline \multicolumn{10}{|c|}{ Рекомендуемая схема } \\
\hline Отстойник с песколовкой & 777 & 20 & 97,4 & 100 & 45 & 55 & 1155133 & 1155133 & 0 \\
\hline Скорый напорный фильтр & 20 & 0,8 & 96 & 45 & 32,4 & 28 & 1155133 & 981863,1 & 15 \\
\hline Кавитационная установка & 0,8 & 0 & 100 & 32,4 & $\begin{array}{l}0,03 \\
10^{-12}\end{array}$ & 100 & 981863,1 & единично & 99,9 \\
\hline $\begin{array}{l}\text { Общая эффективность } \\
\text { очистки }\end{array}$ & \multicolumn{9}{|c|}{99,96} \\
\hline
\end{tabular}


Таблица 2. Сравнение токсичности при очистке стока традиционным и предлагаемым методами

\begin{tabular}{|c|c|c|c|c|}
\hline \multirow{2}{*}{$\begin{array}{c}\text { Культура биотеста } \\
\text { Clorella }\end{array}$} & \multicolumn{2}{|c|}{ Острая токсичность, 72 часа } & \multicolumn{2}{|c|}{ Хроническая токсичность, 7 суток } \\
\cline { 2 - 5 } & $\begin{array}{c}\text { Традиционный } \\
\text { метод }\end{array}$ & $\begin{array}{c}\text { Предлагаемый } \\
\text { метод }\end{array}$ & $\begin{array}{c}\text { Традиционный } \\
\text { метод }\end{array}$ & $\begin{array}{c}\text { Предлагаемый } \\
\text { метод }\end{array}$ \\
\hline $\begin{array}{c}\text { Первоначальное } \\
\text { количество, шт. }\end{array}$ & \multicolumn{2}{|c|}{ Количество погибших, шт. } & \multicolumn{2}{|c|}{ Количество погибших, шт. } \\
\hline 105000 & 38850 & 617 & 63000 & 7350 \\
\hline $\begin{array}{c}\text { Эффективность } \\
\text { предлагаемого } \\
\text { метода }\end{array}$ & В 63 раза меньше погибших & \multicolumn{2}{|c|}{ Токсичность меньше на $93 \%$} \\
\hline
\end{tabular}

и более численности клеток водорослей в опыте по сравнению с контролем за 72 часа биотестирования (условно «острая токсичность») и 7 суток (условно «хроническая токсичность»).

Снижение токсичности обработанной воды наблюдается в 63 раза по сравнению с контролем, что свидетельствует о полном разложении нефтепродуктов до низкомолекулярных, нетоксичных веществ. Общее снижение токсичности составляет $93 \%$, в то время как в традиционной схеме с флотатором общее снижение составляет 40 \% (табл. 2).

\section{Список литературы}

[1] Дубровская О.Г., Андруняк И.В., Приймак Л.В. Ресурсосберегающие технологии обезвреживания и утилизации отходов предприятий теплоэнергетического комплекса Красноярского края: монография. Красноярск: Сиб. федер. ун-т, 2014. 164 с.

[2] Дубровская О.Г., Евстигнеев В. В., Кулагин В.А. // Журнал СФУ. Техника и технологии. 2011 (4). № 6. 665-675.

[3] Евстигнеев В.В. Автореф. дис. ... канд. техн. наук. Красноярск, 2012. 19 с.

[4] Дубровская О.Г., Евстигнеев В.В., Кулагин В.А. // Безопасность жизнедеятельности. 2012. № 3. C. 26-30.

[5] Kulagin V.A., Kulagina L.V., Kulagina T.A. // Journal of Siberian Federal University. Engineering \& Technologies. 2008. (1). Issue 1. 76-85. 